\title{
THE SHIFT FROM THE RURAL LIVELIHOOD IMPROVEMENT PROGRAM TO A MOVEMENT IN JAPAN
}

\author{
Kazuko Tatsumi* \\ Faculty of Economics, Fukuoka University, Fukuoka, Japan \\ *Corresponding author: E-mail: ktatsumi@fukuoka-u.ac.jp
}

Citation: Tatsumi, T. 2021. The Shift from the Rural Livelihood Improvement Program to a Movement in Japan. J. Asian Rur. Stud. 5(2): 111-125

\begin{abstract}
Rural communities have long endured poverty, and they continue to tackle the problems of depopulation, a declining birth rate, and an aging population in Japan. Some rural communities face a crisis of survival. The question of this study are how sustainable communities in rural areas are being created. This study examine the process by which rural women have transformed the Livelihood Improvement Program (LIP) into a movement. The process was to expand rural women's activities to enable them to play an active role in their family, women's groups, and their community. This expansion reflects the effects of the LIP in rural areas. The LIP was started by the Ministry of Agriculture and Forestry in Japan in 1948 to develop selfreliant farmers. The women tried to find solutions to their problems using LIP approaches including problem-solving and the three-by-five cognitive method in group discussions. The LIP was a long-term program and officially ended in 2004. However, the LIP has been continued as a movement for the sustainable development of their community by the women. This study focuses on a case study at the community level involving an update of the LIP program in Yamaguchi Prefecture. The analysis is based on a literature review, secondary and historical data, and fieldwork carried out between 2004 and 2020. From a medium- to long-term viewpoint, their self-confidence improved and they became self-reliant famers. Now women in the older generations are creating employment opportunities through community businesses so that the younger generations may choose to remain in the rural areas in the future. There has been an increasing tendency for young people who moved to the cities to study or work to return to their hometowns. This study found that the most important aspects in susutainable community development are people's initiative, identity, and pride.
\end{abstract}

Keywords: Livelihood Improvement; Community-based Development; Independent Evolvability; Self-reliant Farmers; Rural Women

\section{Introduction}

Rural communities in Japan are facing serious problems in relation to poverty, depopulation, a declining birth rate, and an aging population. Now some rural communities face a crisis of survival.

In 1945, Japan was defeated in World War II. During the immediate post-war years, people suffered from starvation, malnutrition, poor sanitary conditions and a lack of sufficient income. During the subsequent period of high economic growth in the 1960s, depopulation in rural areas increased significantly. Traditional cultures and communities were often seen as obstacles to development, as in general, rural development was equated with economic development. As a result of the urbanization of Japan, labor migration in search of better wages led to the ongoing depopulation of rural areas. As 
urban areas attracted more people, ideas, and commodities, the younger generations abandoned their rural communities to move to the cities.

Odagiri (2011) identified four aspects of this degradation. First, in the 1960s, depopulation progressed significantly in rural areas. Second, since the mid-1980s, the degradation of land used for farming and forestry has also progressed at a remarkable rate. Third, since the 1990s, there has been a gradual degradation of community functions. Finally, at a deeper level, there has been a degradation of pride. Rural areas have become sparsely populated, and aging rural societies are feeling the negative effects of the departure of the younger generations. Thus, rural people are gradually losing their pride in their communities (see Figure 1).

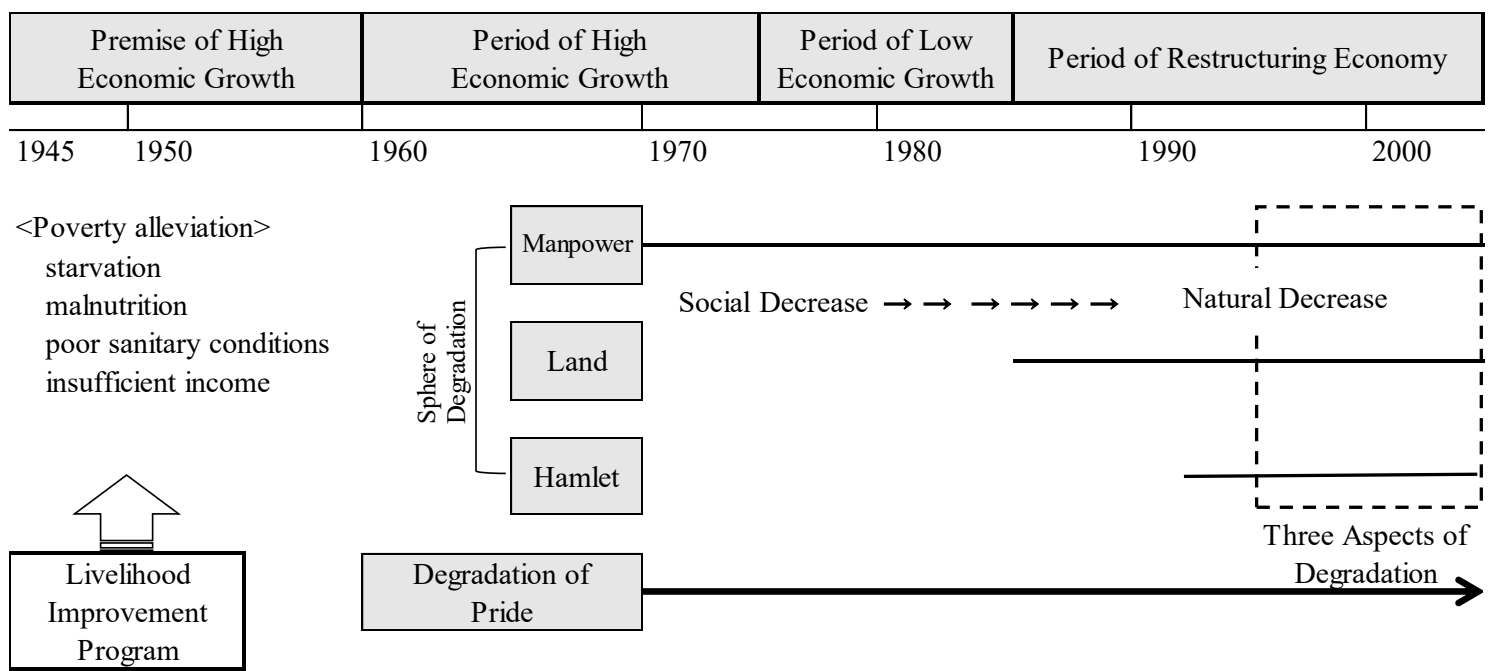

Self-reliant farmers $\rightarrow$ Maintain pride (especially among women) in rural areas $\rightarrow$ social evaluation and confidence

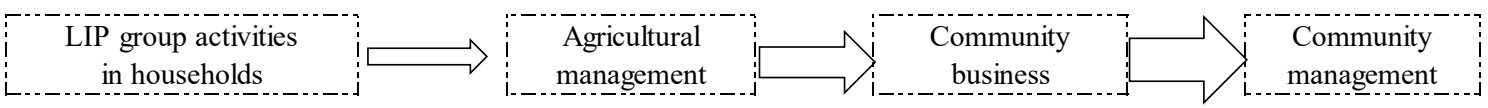

Source: The author, based on Odagiri (2011)

Figure 1. Livelihood Improvement and Four Aspects of Degradation

Contrary to Odagiri's (2011) findings, some women did not lose their pride, but rather tried to find solutions to these problems using problem-solving approaches and the threeby-five cognitive method. These approaches were supported by the Livelihood Improvement Program (LIP), which was introduced by Japan's Ministry of Agriculture and Forestry (MAF) in 1949 to develop self-reliant farmers. Ogura (1951) defined selfreliant (independent minded) farmers as those who were not dominated by their social environment and traditional customs, but thought deeply with an independent mind, seeking ways to lead a better life. They were seen as the key to building a democratic society. They could think and act with initiative and take responsibility for their decisions (Yamaguchi Prefecture, 1969). In post-war Japan, the daily lives of women in rural communities tended to involve farm work and housework and they had low status. Therefore, the LIP focused on women, and LIP workers traveled to the villages and listened to these previously voiceless women. This study focuses on rural women's activities in Japan. 
Sato (2005) identified lessons from the LIP in post-war Japan that could be applied to rural development projects in developing countries because post-war Japan had faced almost the entire array of problems many developing countries face today. The Japan International Cooperation Agency (JICA) referred the lessons learned from the LIP to rural development projects in developing countries (JICA, 2009). They focused on the lessons learned during the first phase of the LIP, from 1948 to 1965, which was aimed at alleviating poverty in rural areas. Although these adaptations are important, these perceptions of rural development are defined by the donors who provide development assistance. Their most projects are fixed-term projects (3 years or less). From a short-term viewpoint, it is not clear to show a model of sustainable rural development.

From a medium- to long-term viewpoint, this study focuses on the process by which these rural women have transformed the LIP into a movement. This study regards the first phase as having laid the groundwork for the Livelihood Improvement Movement. The second phase, from 1965 to 1988, focused on improving daily life in times of rapid economic growth, and the third phase, from 1989 until the program ended in 2004, created employment opportunities through grass roots activities (Tomita 2011). However, the LIP has continued as a movement at the grass roots level by the women who continue to work in rural areas.

As a result of these activities, their self-confidence increased and they became selfreliant farmers, which made them aware of the importance of traditional cultures and communities. Their initiative, identity, and pride have been developed through community-based activities. This study hypothesizes that the women's movement has a significant role to play in the transformation toward sustainable livelihoods and community development. The experience of these women provides a model for Asian rural development. Some rural communities in Asian countries face similar issues. These are not only poverty alleviation but also the other serious issues.

\section{Method}

The analysis is based on a literature review, secondary and historical data, and fieldwork carried out between 2004 and 2020 in Yamaguchi Prefecture. This fieldwork consisted of interviews with key people, focus-group discussions, participant observations, and process documentation. This approach enabled analysis from the medium-term viewpoint at the national, prefecture, community, family, and individual levels. The author participated in the survey of rural women in Yamaguchi Prefecture in 2015 as a committee member (Yamaguchi Prefecture, 2016). There were 1,892 respondents, a response rate of $84.7 \%$

In 2019, Japan's annual report on the aging society revealed that $34.3 \%$ of the population in Yamaguchi Prefecture were aged 65 or older, which was higher than the national average of $28.4 \%$ (Cabinet Office, 2019). This was the third-highest figure in the country, and is increasing at a faster rate in Yamaguchi Prefecture than elsewhere in Japan, although it is predicted to be the national average in 10 years' time.

Yamaguchi Prefecture is located in the westernmost part of Japan, and is surrounded on three sides by the sea, with the Chugoku mountain range running from east to west (see Figure 2). Agriculture is the main industry in this prefecture. The 2015 Census of Agriculture and Forestry reported that $77 \%$ of the agricultural workforce was aged over 65 , with an average age of 70.3 years, the second highest figure in Japan. The report also 
showed that $51.5 \%$ of farmers were female (MAFF, 2015). The survey of rural women in Yamaguchi Prefecture in 2015 showed that $57.5 \%$ of women participated in decisionmaking regarding agricultural management (Yamaguchi Prefecture, 2016), up from the figure of 40.1\% reported in the corresponding survey in 1999 (Yamaguchi Prefecture, 2000). Thus, it can be seen that this prefecture has made an effort to promote women's activities in relation to rural development. There is a sense of the LIP underlying their activities. Even though the LIP ended in 2004, Yamaguchi Prefecture continued to support the positions of LIP workers until 2011. Similar programs are still implemented in a small way today.

The case study reveals the process of shifting from the LIP to a movement in the Shibukawa community in the Kano area in Shunan City, Yamaguchi Prefecture. The Shibukawa community is located in an isolated area surrounded by hills and mountains that is cold in winter and experiences snowfalls. Of the population of $91.7 \%$ were aged 65 or older as at February 2018 (see Figure 3). The LIP group started in 1964, and the Shibukawa Community Improvement Association (SCIA), which includes all households, was established in 2003, when the community was facing a crisis in terms of sustainability. The purpose of the SCIA was sustainable community-based development. The author participated in their study tour to South Korea in 2010 as a form of action research and continues to conduct fieldwork while backing up Shibukawa from behind. This action research was conducted in collaboration with the Shibukawa residents' association, the city office, and the Yamaguchi Prefecture extension center.

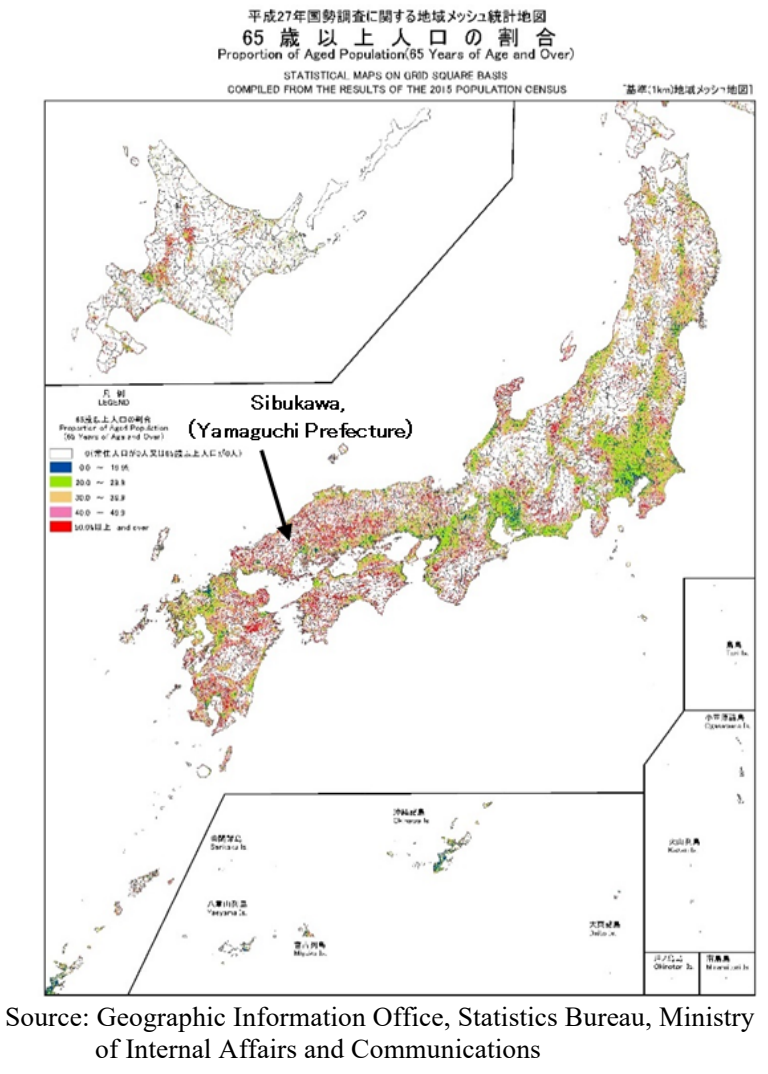

Figure 2. Study Area in Japan

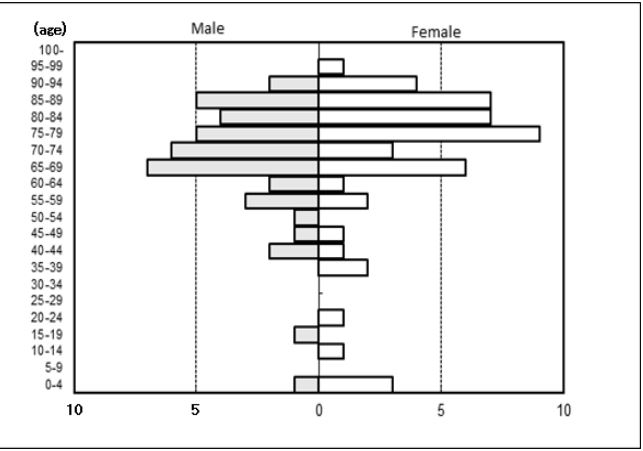

Source: Basic Residents Registers in Shunan City (2016)

Figure 3. The Population Pyramid in the Shibukawa Community 


\section{Results and Discussion}

\subsection{The Livelihood Improvement Program (LIP)}

\subsubsection{The first phase of the LIP (1948-1965)}

The MAF introduced the LIP to Japan in 1949 with the aim of developing self-reliant farmers under the instructions of the General Headquarters of the Allied Forces. The main aim of the LIP was to promote the ideas of "awakening," "solidarity," and "making changes on our own" to women, especially young wives. Previously, housewives had had no such motivation because they were bound by the traditional way of life.

The LIP workers were hired as prefectural government officers to encourage rural development. They had practical and philosophical training at both the prefecture and national level. The practical training included skills for achieving a better home life, for example in relation to food, clothing, housing, and home management.

The LIP workers were stationed in the same office as their male colleagues, the agricultural extension workers, who applied technology to increase production and earnings. The content of the activities that were carried out by the two groups was very different, but the agricultural extension workers and the LIP workers had to work handin-hand if they were to tackle poverty in rural areas.

Initially, the LIP workers searched for ways to enter rural society. They visited the houses and paddy fields and listened to the rural women. Sometimes, they organized gatherings of rural women in their houses or in a public space in the village so that they could talk to each other, and at other times they invited rural women to the extension center. This enabled them to identify the key women and encourage them to become leaders. The LIP workers were the driving force behind the accomplishments of groups of women farmers (see Figure 4). These groups were called Livelihood Improvement Practice groups (LIP groups). The members of these groups could share and solve problems with other group members and workers, enabling them to cope with problems that were unmanageable at the individual level, and providing mutual encouragement leading to personal growth.

Rural areas in post-war Japan were poverty stricken, and people struggled to recover from the devastation caused by the war. The main problems included food preparation, access to water, an unbalanced diet, travel times and distances, and overwork during busy seasons.

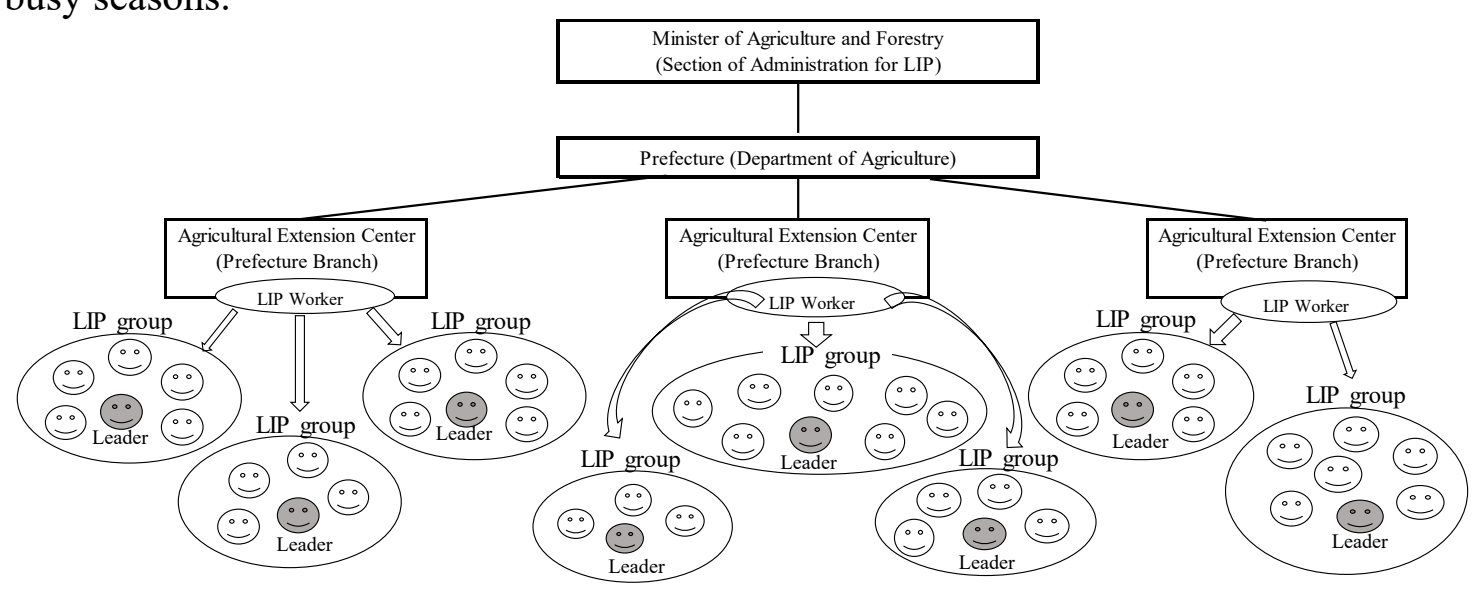

Figure 4. LIP Groups Formed by LIP Workers 


\subsubsection{The second phase of the LIP (1965-1988)}

In 1964, the Olympic Games were held in Tokyo. Japan also joined the Organization for Economic Co-operation and Development and became an Article 8 member of the International Monetary Fund. The Tokaido bullet train began operation, and the mortality rate of infants fell below that of the USA. In summary, Japan shifted from a developing country to a developed country. Thus, the second phase of the LIP, from 1965 to 1988, focused on improving daily life in times of rapid economic growth.

During the period of high economic growth, traditional cultures and communities were often seen as obstacles to development, and rural development was generally equated with economic development. As a result of the ongoing urbanization of Japan, labor migration in search of better wages led to the continual depopulation of rural areas. As the urban areas attracted more people, ideas, and commodities, the children of the LIP group members abandoned the countryside to move to the cities. Their mothers were also inclined to believe that their children would be better off in urban areas.

As farming became more mechanized, fewer workers were needed, and thus more workers moved to the cities, leaving mainly women and the elderly in the rural areas. Therefore, the women were forced to learn to financially manage the household and to use agricultural machines. They supported each other by sharing their individual experiences and ideas, and their groups undertook numerous intensive rural life improvement activities.

\subsubsection{The third phase of the LIP (1989-2004)}

The most severe challenges were the ongoing urbanization during the period of high economic growth and the ongoing depopulation and aging in rural areas. When the population is aging and decreasing, traditional culture is gradually lost and is unlikely to be passed on to future generations. As a result of this degradation, the rural areas became sparsely populated and the increasingly aging rural societies felt the negative effects of the exodus of the younger generations. Since the 1990s, the degradation of community functions has continued. However, these changes are only symptoms. The underlying cause was damage to people's pride, resulting in a loss of confidence.

The degradation of pride was working at a deeper level. People were gradually losing pride in their community because there were few resources, few opportunities, little enjoyment, and a lack of information. However, the LIP groups and LIP workers remained undaunted, and tried to find solutions to these problems using problem-solving approaches and the three-by-five cognitive processing method during group discussions (see Table 1).

Table 1. Three-layer Five-stage Cognitive Method used in the Livelihood Improvement Program

\begin{tabular}{|c|c|c|c|c|c|}
\hline & Awareness & Clarify problems & Hypothesis & Think theoretically & Trial \\
\hline Action & $\begin{array}{l}\text { Consciousness } \\
\text { regarding daily life }\end{array}$ & Record & $\begin{array}{l}\text { Visit and observe } \\
\text { activities in advance }\end{array}$ & Grasp condition & Trial \\
\hline Thinking & Talking with someone & Clarify problems & $\begin{array}{l}\text { Hypothesis for } \\
\text { solving problems }\end{array}$ & $\begin{array}{l}\text { Possibility to } \\
\text { actuality }\end{array}$ & Rethinking hypothesis \\
\hline Learning & $\begin{array}{l}\text { Reading books and } \\
\text { attending lectures }\end{array}$ & Study & $\begin{array}{l}\text { Research activities in } \\
\text { advance }\end{array}$ & Asking professionals & Analysis application \\
\hline
\end{tabular}


During the third phase, from 1989 to 2004, they created employment opportunities through grass roots activities such as farm stands selling agricultural and processed products to potential newcomers and returning family members in an attempt to persuade them to stay in the area.

The program officially ended in 2004 following an amendment to the Agricultural Improvement Promotion Law. However, the activities of the LIP groups have continued in the form of Livelihood Improvement Movements in a few prefectures.

\subsection{The Case Study of Yamaguchi Prefecture}

\subsubsection{The second phase of the LIP (1965-1988) in Shibukawa}

$<$ Participation in LIP groups $>$

In the 1960s, most marriages in Shibukawa were arranged, thus the women moved to Shibukawa from other areas. Initially, they had no friends, but the local women invited the young newcomers to participate in the LIP group. They were able to share information and learn new skills from the other members, but one of the first steps for the newcomers was to respect the traditional customs of Shibukawa.

$<$ Household improvement activities $>$

In the 1960s, the LIP group's activities focused on improved cooking facilities and nutrition. At first, the older generation in Shibukawa disapproved of the women's desire to spend time on their group's activities. However, after being convinced of the importance of these activities by their LIP worker, the older generation became more understanding of the new role women could play in both the family and the community. $<$ Study tour outside the city $>$

In 1975, the Shibukawa LIP group visited another group outside the city. This group had their own meeting place where they processed their products. On the bus on their way home, the Shibukawa LIP group decided that they also needed a processing center. "Let's make it happen!" they agreed, and so they each began to save 1,000 yen each month to contribute toward making this dream a reality. Eventually, they accumulated one million yen, but this was insufficient, so acting on the advice of the extension worker, they borrowed a further two million yen in the form of a special subsidy loan. For reference, the average annual salary of women college graduates in 1978 was about 123,315 yen in Yamaguchi Prefecture (Yamaguchi Prefecture 1980).

$<$ Starting a local business and establishing their own processing center $>$

Their husbands thought it would be impossible for the women to repay the loan because they believed that the women were not good at financial management. However, by 1979, the women had opened a small restaurant with the aim of using the profits to pay off the loan. At first, the group struggled with the set up and running of the new restaurant, but with assistance from the LIP worker and the local government director, the women managed to succeed, and by 1980, the dream of having their own processing center had become a reality. By 1985 they had repaid the loan, and thus the profits from the restaurant no longer needed to be applied to loan payments.

\subsubsection{The third phase of the LIP (1989-2004) in Shibukawa \\ $<$ Participation in community activities $>$}

Since the entry into effect of the revised Special Mergers Law in 1999, local governments had merged and grown larger. In 2002, the LIP group conducted interviews 
and distributed questionnaires in an effort to deepen their understanding of Shibukawa. Responses included statements such as "Local government may abandon the remote areas" and "We have to be independent." Through this research, the group found that most people were worried about the future of Shibukawa. They thought that the relationship between the Shibukawa community and the local government was strained, and that they may abandon the remote areas, even though $73 \%$ of the people wanted to participate in community activities.

$<$ Establishing their community-based association>

The group asked all local households to participate in a seminar. At the time, the local men did not appreciate the importance or potential value of the seminar, and were reluctant to participate, dismissing it as a women's gossip meeting. While the men had initially misunderstood the aim of the seminar, they soon realized that the women were capable of organizing themselves, and wanted them to continue. The group was based on the community, and it was called the "Shibukawa Community Improvement Association (SCIA)."

$<$ First female community leader $>$

The emergence of a female leadership role was a first for Shibukawa. The LIP worker in charge of Shibukawa recalled:

"I was impressed at the time. There was a social trend against women appearing at state occasions, and if the local men asked a woman to become a leader, in most cases she politely refused. However, the women in Shibukawa accepted the roles of leader and director. This was an historic moment. I thought that Shibukawa would be changed from now on" (interview in March 2008).

$<$ Social evaluation of women $>$

With the government recognizing the women's achievements, the men's confidence in their wives' abilities as leaders grew. Because of this, and the successful results of their activities, feelings of pride and self-worth continued to grow within these women, and this continues today. In 2007, they were awarded a prize for excellence in the category of active seniors in rural areas by the Ministry of Agriculture, Forestry and Fisheries.

$<$ Collaborative activities organized by the SCIA $>$

Their first action of the SCIA was to evaluate the situation to clarify what the problems were and prioritize them. They repaired the community infrastructure and cleaned the roads, and planted flowers on abandoned farmlands. Their traditional culture was reevaluated, and a book was compiled listing everyone's skills.

$<$ Shibukawa vision and resource map $>$

The SCIA adopted the LIP approach to create a vision and resource map during their meetings, which included men. To solve the problem of depopulation, they tried to develop the Shibukawa community to the point where younger generations were encouraged to return to live in Shibukawa.

\subsubsection{Shifting the LIP to a movement}

$<$ Exchange program with urban people $>$

The activities of the SCIA expanded to include exchanges with people in urban areas. The women had all been newcomers themselves at some point over the previous 60 years, and had learned how to adapt to Shibukawa. Thus, they were able to provide advice to newcomers from urban areas. As a result, by 2013, four families from urban areas had 
settled in Shibukawa and a further 16 families had purchased second houses for weekend visits. The people who moved from the city to reside in a rural community were called "I-turners."

$<$ Planning the new processing center $>$

Shibukawa's primary school closed in 2009 and was demolished in 2010. The SCIA needed to develop a range of processed products, and decided to establish a new community center and processing center on the former site of the school. The SCIA met one-third of the costs, doing the building work themselves using timber sourced from common forests. The remaining two-thirds of the costs were met by city and prefecture subsidies.

$<$ Study tour to Korea $>$

Five women from Shibukawa visited a rural area (Haenan City, South Jeolla Province) in Korea from 5 March to 11 March in 2010 for a study tour. They learned how to cook kimchi (pickled vegetables) and how their Korean counterparts processed kimchi in the traditional way, with a view to developing their own range of processed products. They also discussed common problems of depopulation, a lack of successors, and low agricultural income in rural areas.

$<$ Women's initiative regarding the study tour $>$

The women planned the tour without the assistance of their LIP worker, and paid for it themselves. They showed initiative by coordinating the tour through Yamaguchi University, Yamaguchi Broadcasting, the Institute for Japan-Korea Agriculture and Rural Area Culture Studies (a non-profit organization) and the Haenam Cyber Agriculture Research Association.

$<$ Support from their husbands $>$

The tour was fully supported by the women's husbands, who understood that this cultural exchange was for the benefit of Shibukawa, as well as for the women themselves. On this occasion, the men were happy to stay at home and cook their own dinners, a first for many of them. As one husband explained:

"This is a new experience. I understood that their tour was in aid of community development. For the first few days, I reheated and ate meals my wife had left in the refrigerator, and was lonely. I called the other husbands, and we got together for a drink. It was only for 1 week...but it seemed like a very long time. I came to appreciate the value of my wife" (interview in March 2010).

$<$ Welcoming a study group from Korea $>$

Fifteen people from the Haenan Cyber Agriculture Research Association and other administrative offices in Korea visited Shibukawa from 1 July to 5 July in 2010. The SCIA hosted them, and having initiated the mutual exchange of ideas and solutions in rural areas, the groups continue to encourage and support each other today.

$<$ New processed products for the LIP group $>$

The women who had remained in Shibukawa listened to the reports of the women who had visited Korea, and followed their lead on how to make kimchi in the traditional way. They then put this knowledge to good use by developing their own Shibukawa kimchi in 2011.

$<$ Agricultural organization established by husbands $>$

Having been inspired by the women, their husbands formed the Shibukawa Agricultural Organization in 2011. Their activities included growing the variety of 
Chinese cabbage used in kimchi and lending support to the women's activities. At the same time, the Shibukawa community center was built, along with the women's new processing center.

\section{$<$ Local businesses commenced by U-turners $>$}

The strategy pursued by the women of Shibukawa is gradually coming to fruition. In 2018, the restaurant that had been started by the LIP group in 1979 was renovated. The restaurant's name "Tenkuu Cafe" means "Open Sky Cafe," and the women's children and grandchildren, as well as visitors from urban areas, visit Shibukawa to eat there. A couple of U-turners who returned to husband's hometown opened a farmer's restaurant in Shibukawa in 2007. And their daughter returned to Shibukawa in 2016 and opened a bakery shop in 2017 . The restaurants and bakery shop operate on the principle of "the value of trust and safety."

\subsubsection{Lessons from Shibukawa's movement}

Throughout the women's history in Shibukawa, LIP workers traveled there and listened to these previously voiceless women. The women of the Shibukawa LIP group have continued to tackle ongoing problems using LIP approaches including problemsolving and the three-by-five cognitive method in group discussions. Initially, their activities were restricted to within their own household, but they gradually developed a range of group activities. Finally, they expanded their areas of activity to include community development, creating a community-based social network (see Figure 5).

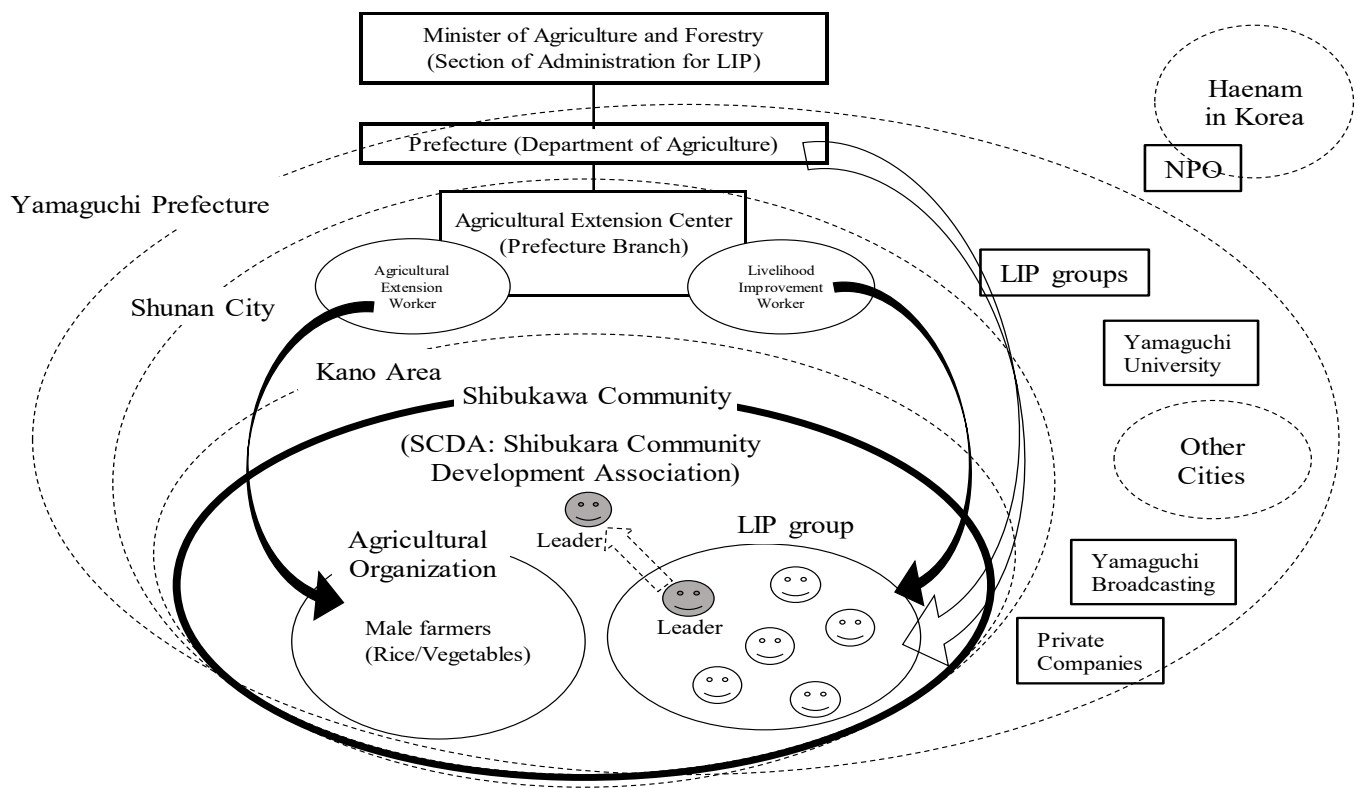

Figure 5. Relationships with Other Actors in Shibukawa

This shows that a historic impediment rooted in sexism has started to be overcome because both the men and women in the community recognize that working together is the only way to ensure that a future exists in Shibukawa for younger generations. As a result of their struggle, women are now accepted as fully fledged members of the local 
community. They have gained in self-confidence and gradually become self-reliant farmers. In Shibukawa, the Livelihood Improvement Movement has evolved from the LIP to include the men. The leader of the LIP group commented:

"We have pride, and therefore we have meaning in our lives. Don't look down on us.

There were a lot of hard times, but there were a lot of fun times too. We were able to share our problems, hopes, and ideas. The members of the LIP group have made me what I am today" (interview in March 2008).

The SCIA has inspired all residents of the community to join in the rural community spirit of camaraderie, and even though the women and men are now in their seventies, they have no plans to retire. The future of the community relies on the sustainability provided by the women's movement's ability to provide sufficient employment opportunities and community spirit to entice potential newcomers (I-turners) and returning family members to stay.

If I-turners are to stay, it is essential that they recognize the pride that exists within the rural community. This is embodied most clearly in the attitude of the women. Most women were newcomers to Shibukawa at the time of their marriage. Initially, they had no friends, but the female members of the community invited the young newcomers to participate in the LIP group. One of the first steps for the I-turners was to learn to respect the traditional customs of Shibukawa, and thus it is they, and not the men, who can best understand the cultural gaps and uneasy feelings of the I-turners. Obikwelu, Ikegami, and Tsuruta (2017) noted that I-turners' livelihood is not only dependent on their financial bases, but also on their social relationships with original villagers.

As a general tendency, young residents in urban areas are showing increasing interest in rural areas, and are keen to find a clean environment and adopt a new lifestyle. Older people are increasingly looking to settle in rural areas after their compulsory retirement. A 2014 White Paper noted a higher level of awareness among young people about the "Return to the Countryside" movement. Comparing the 2005 and 2014 surveys of metropolitan residents' desire to settle in rural areas, it increased from $17.0 \%$ to $32.7 \%$ for those in their 30s and from $15.9 \%$ to $35.0 \%$ for those in their 40s (MLIT, 2014). Furthermore, it is clear that metropolitan area residents who originally came from rural areas have the most pride in their place of origin. In the future, it is expected that this trend will increase as a result of to the coronavirus. Thus, the strategy adopted by the rural women in Shibukawa will gradually come to fruition.

These movements developed not only in Shibukawa, but also in other rural communities. As of June 2020, 151 LIP groups continued to operate in Yamaguchi Prefecture. Some groups visited Shibukawa to learn the SCIA's approach and exchanged their information and ideas mutually. In 2003, young women made not a group but network. The name is "Voice." This is a new movement beyond their communities.

The findings of the 2015 survey of rural women in Yamaguchi Prefecture are shown in Figures 6 (Yamaguchi Prefecture, 2016). In response to the question "What did you gain from group activities?" the respondents (female farmers) answered "More friends" (56.8\%), "Enjoyment" (40.7\%), "New knowledge and skills" (28.7\%), "A feeling of contributing to society" (27\%), "Expanding my range of activities" (20.5\%), "Increased interest in social issues" (18.9\%), and "Relief from stress" (13.3\%). 


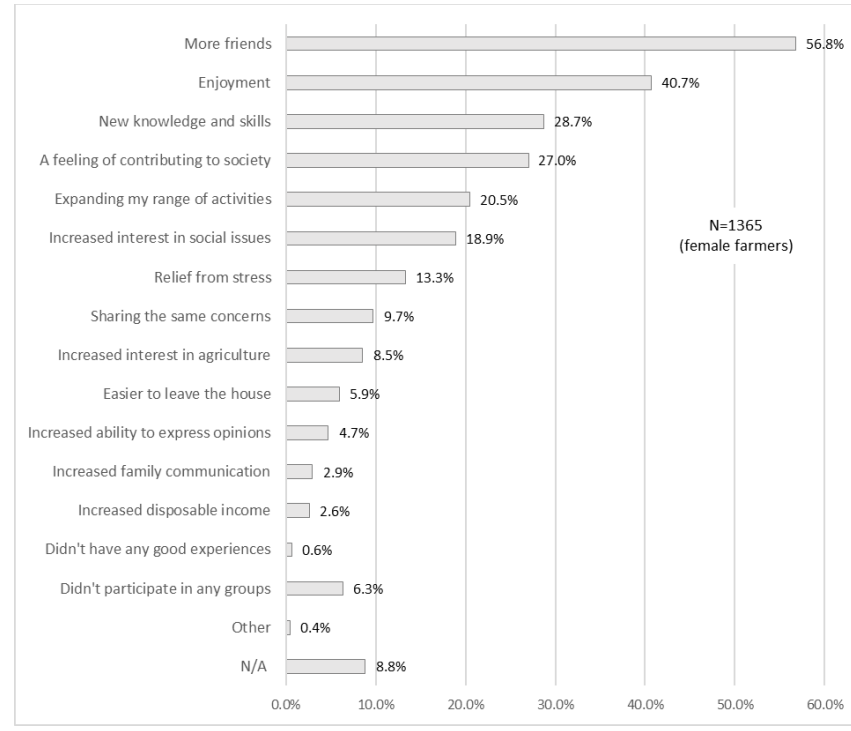

Source: Yamaguchi Prefecture (2016)

Figures 6. What did you gain from group activities? (Multiple answers permitted)

\section{Conclusion}

The key aim of the LIP was to create self-reliant farmers, which cannot be done solely through excellent slogans and plans. To succeed in practice, human development is necessary so that the newly self-reliant farmers are able to think for themselves and then act, taking responsibility for their decisions. Over time in Shibukawa, attempts at improving daily life shifted from a program to a movement, which reflects the process of human development. They became actors in the development of their own initiative. The women in Shibukawa assumed an important role in enabling the shift to "( I ) independent evolvability," as shown in Figure 7.

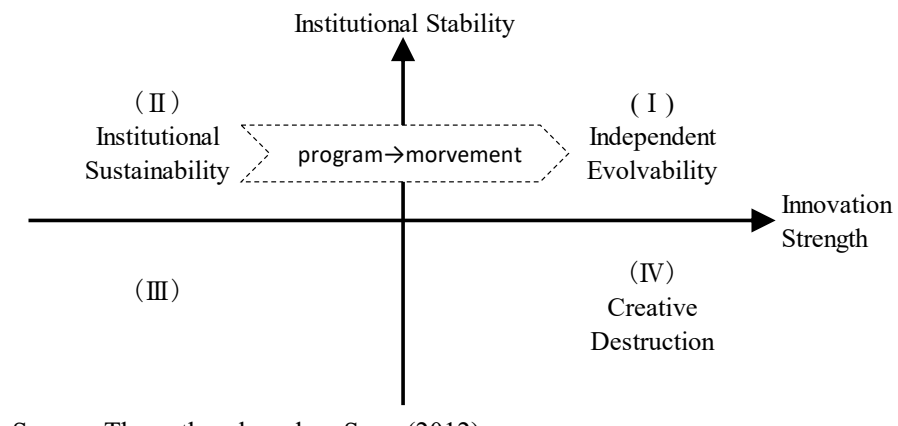

Source: The author, based on Sano (2012)

Figure 7. Three Types of Sustainability

Sano (2012) examined sustainability in relation to development assistance projects and suggested that there were three types of sustainability: independent evolvability, that is, strong innovation as a result of the actor's engagement with the institution, which in turn keeps the institution in a state of equilibrium within the system; institutional 
sustainability, that is, high stability of the institution as a result of the low level of innovation by the actors making use of the institution; and creative destruction, that is, an unstable institution as a result of a high level of innovation by the actors (see Figure 7).

Figure 7 shows the process of "( II ) institutional sustainability," and the importance of the LIP's administrative system cannot be overemphasized. From a medium- to longterm viewpoint, the administrative support provided by the LIP was both systematic and flexible, based on face-to-face relationships. There were numerous training programs at both the prefecture and national levels for LIP workers, who acted as facilitators, shining light on actors from behind the scenes and coordinating synergistic relationships with various organizations. Even though the program officially ended 2004, it dealt with problems including poverty alleviation, gender issues, depopulation, aging, disasters, and welfare for 55 years. Based on Sano's findings, the process of shifting from the LIP to a movement was an example of "( I ) independent evolvability."

This study highlights the women's struggle in response to depopulation combined with a diminishing number of young people and an aging society. However, the problems remain unsolved. Thus, this is a continuous initiative, requiring ceaseless effort. Even those women who have had considerable experience addressing the issues related to improving daily life are still trying to tackle the problems that they face in the quest for sustainable livelihoods and community development.

The term of sustainable livelihoods was used formally by Robert Chambers and Gordon Conway in 1991 in development studies (Chambers and Conway 1992). The Department for International Development adapted their definition and noted "a livelihood comprises the capabilities, assets and activities required for a means of living." These capabilities and assets can be divided into five types of capital (human, social, natural, physical and financial). Human capital (knowledge and labor or the ability to command labor) is required in order to make use of any of the four other types of assets (DFID 1999). This study found that the most important aspects in the human capital are people's initiative, identity, and pride, which have been developed through communitybased activities. Ikegami (2019) noted that it is necessary for development studies to change their conventional assumptions and recognize the people as actors who need to take the initiative regarding their own development.

This study has some limitations because of not including agricultural and environmental issues. The best approach will be different according to the natural, social, economic and cultural conditions of rural areas. It is important to focus on how to promote activities rather than what types of activities should be undertaken (Mizuno, 2019). Thus, it is possible for development study scholars to provide ideas and solutions based on mutual learning in Asian countries.

\section{Acknowledgments}

This paper is based on a presentation given at the 6th Asian Rural Sociology Association Conference (ARSA2018) on 27 August 2018 at Hasanuddin University, Makassar, Indonesia. The author appreciates the valuable comments of the participants and is grateful to Dr. Sagar Sharma (Kathmandu University, Nepal) and Councilor Patrick Kelly BSc (Hons) (Dartford Borough Council, UK) for their advice. The author would like to express her thanks to all their friends in Yamaguchi Prefecture for their kind help. This work was supported by JSPS (KAKENHI Grant Numbers 26301028 and 
JP19H01584). The author thanks Geoff Whyte, MBA, from Edanz Group (https://enauthor-services.edanz.com/) for editing a draft of this manuscript.

\section{References}

Cabinet Office, Japan. 2019. Annual Report on the Ageing Society.

Chambers, R., and G.R. Conway. 1992. Sustainable Rural Livelihoods. IDS Discussion Paper No. 296. University of Sussex, Brighton.

DFID (Department for International Development). 1999. Sustainable Livelihoods Guidance Sheets. https://www.ennonline.net/dfidsustainableliving, Download 25 March 2021.

Ikegami, Koichi. 2019. A Perspective of Agricultural and Rural Studies under the Era of SDGs. Journal International Development Studies 28(1): 1-17 (English abstract).

Ito, Yuko. 2010. "Three-by-Five Process Method" for Visible Process Development. Journal of International Development and Cooperation. 16(2): 171-188 (English abstract).

JICA (Japan International Cooperation Agency). 2009. Lessons from Livelihood Improvement Experiences in Postwar Japan. https://jica-netlibrary.jica.go.jp/lib2/05PRDM008 e/next02 01.html, Download 11 June 2017.

JICA (Japan International Cooperation Agency). 2011. Wisdom of the Livelihood Improvement (KAIZEN) in Post-War Japan.

MAF (Ministry of Agriculture and Forestry, Japan). 1969. Seikatsu kaizen fukyuu jigyou 20 nen no ayumi (The 20-year History of the Livelihood Improvement Program).

MAFF (Ministry of Agriculture, Forestry and Fisheries, Japan). 2015. Census of Agriculture and Forestry.

MLIT (Ministry of Land, Infrastructure, Transport and Tourism, Japan). 2014. White Paper on MLIT in Japan.

Mizuno, M. and T. Horiguchi (eds.). 2019. Improvement Approach for Livelihood. Koyo Shobo, Kyoto (in Japanese).

Obikwelu, F.E., Ikegami, K., Tsuruta, T., 2017. Factors of Urban-rural Migration and Socio-economic Condition of I-turn Migrants in Rural Japan. Journal of Asian Rural Studies. 1(1): 70-82.

Odagiri, T. 2011. Rural Regeneration in Japan. Centre for Rural Economy Research, University of Newcastle upon Tyne, Newcastle.

Ogura, T. 1951. Noumin to Kyouiku (Farmer and Education). Nourin Toukei Kyoukai, Tokyo.

Sato, K. H. 2005. 'Livelihood Improvement' in Postwar Japan. Gender and Development. Ed., Murayama, M. Palgrave Macmillan, Basingstoke, pp: 68-84.

Sano, M. 2012. Examining Sustainability in Development Assistance Projects. Journal of International Development Studies, 21(1/2): 47-57 (English abstract).

Tatsumi, K. 2012. A Study on the Sociological Approach of Rural Development. Journal of International Development Studies, 21(1/2): 73-88 (English abstract).

Tatsumi, K. 2013. Gurokal na mura dukuri niokeru nouson jyosei no yakuwari (The Roles of Rural Women in Global and Local Development). NOU No. 293. Agricultural Policy Research Committee, Tokyo. 
Tomita, S. 2011. Nousangyoson niokeru seikatu kaizen toha nandattanoka (What does the Livelihood Improvement Program mean for Rural Societies?): 28-58. In Kurashi no Kakumei (The Revolution of life). Noubunkyo. Tokyo.

Tsutsumi, M. (eds.). 2010. A Turning Point of Women. Gakubunsha. Tokyo.

Yamaguchi Prefecture. 1969. Fukyujigyo 20 nen no Ayumi (The 20-year History of the Extension Program). Yamaguchi.

Yamaguchi Prefecture. 1980. Yamaguchi Ken Toukei Nenkan (Yamaguchi Prefecture Statistical Yearbook). Yamaguchi.

Yamaguchi Prefecture. 2000. Nousan Gyoson jyosei no ishiki chousa houkokusyo (The Report of the Awareness Survey of Rural Women). Yamaguchi.

Yamaguchi Prefecture. 2006. Yamaguchi ken ni okeru nousangyoson jyosei no seikatsu kaizen wo sasaeta seikatsu kairyou fukyuuin no sokuseki wo otte (The Livelihood Improvement Workers who supported the Livelihood Improvement Activities in Rural Areas of Yamaguchi Prefecture). Yamaguchi.

Yamaguchi Prefecture. 2016. Dai 3 ji Yamaguchi ken nousangyoson jyosei nikansuru chuutyouki bijyon (The Mid Term Vision for Rural Women in Yamaguchi Prefecture: The Third Phase). Yamaguchi. 